\title{
Challenging Orthodontic Treatment for a Patient with an Impacted Maxillary Canine: A Case Report \\ Elyes Hassouna $^{1 *}$, Saadi Nada ${ }^{1}$, Dallel Ines ${ }^{2}$, Tobji Samir ${ }^{2}$, Ben Amor Adel ${ }^{2}$
}

\author{
${ }^{1}$ Resident in Dento-Facial Orthopedics at the Monastir Dental Clinic, Monastir University, BP 56 Avenue Taher Hadded, Monastir \\ 5000, Tunisia \\ ${ }^{2}$ Professor in Dento-Facial Orthopedics at the Monastir Dental Clinic, Monastir University, BP 56 Avenue Taher Hadded, Monastir \\ 5000, Tunisia
}

\author{
DOI: $10.36347 /$ sjds.2021.v08i01.010 \\ | Received: 07.01.2021 | Accepted: 25.01.2021 | Published: 30.01.2021 \\ *Corresponding author: Elyes Hassouna
}

Abstract

The clinical case described in this article represents a case of a 22 years old patient with impacted canine complicated by transversal alveolar deficit, an anterior open bite with a tendency to skeletal Class III and concave profile. This case was treated in the orthodontic department at the Monastir Dental Clinic. The delicate management of space constituted the major difficulty of this case, as the patient had a big crowding and a high risk profile eliminating any extraction option to create the space needed. This malocclusion led to severe consequences on both esthetic but most importantly functional levels. Close collaboration between orthodontist, parodontologist and occlusodontist was necessary in order to successfully handle this case and it had significantly improved the life quality of this patient.

Keywords: Maxillary impacted canine, corticotomy, transversal deficit, crowding.

Copyright ( $(2021$ The Author(s): This is an open-access article distributed under the terms of the Creative Commons Attribution 4.0 International License (CC BY-NC 4.0) which permits unrestricted use, distribution, and reproduction in any medium for non-commercial use provided the original author and source are credited.

\section{INTRODUCTION}

Impaction of maxillary canines is a clinical problem encountered frequently; they are the most commonly impacted teeth, second only to third molars [1]. Maxillary canine impaction occurs in approximately $2.83 \%$ of the population in Tunisia, slightly higher than the standard frequency (1-2\%) and it is twice as common in females as it is in males. The canine impaction rate is twice as high in the maxilla as compared to the mandible [2]. Of all patients who presented the affected upper canines, $8 \%$ had side effects in bilateral impactions. In addition, two-thirds of all upper-impact canines affect the palatal condition, while only one-third involve a buccal plate $[3,4]$.

The treatment usually requires an interdisciplinary approach. Exposure to affected dental surgery and complex orthodontic procedures used to align a tooth in an arch can lead to a variety of injuries to the supporting structures of the tooth, not to mention long-term and the financial burden to the patient. The common complications of teeth treatment are bone loss, root resorption, and gingival recession. To reduce the treatment time, corticotomy or decortications; simply refers to the intentional cutting of cortical bone; has been frequently used to eliminate the resistance of the dense cortical bone to orthodontic tooth movement. Moreover, it has been stated that corticotomy facilitated orthodontics decreases the undesirable adverse effects of orthodontic treatment including root resorption and periodontal damage.

This paper describes the clinical management of labially impacted canine. It illustrates the topic by presenting a treatment delivered to a 22 years old male patient, suffering from transversal alveolar deficit, crowding, and shifting of the midline, associated to an open bite and absence of the upper right canine with a high risk profile eliminating any extraction option to create the space needed. Corrective orthodontic therapy was associated to a maxillary expansion by a quadhelix appliance. The affected canine was sent to an orthodontic retreat, after surgery and corticotomy, and was safely returned to the arch. This approach has proved to be very effective in meeting both performance and aesthetic goals.

\section{CASE REPORT}

A 22-year-old male patient reported the dentofacial orthopedics department at the Monastir Dental Clinic with the chief complaint of the absence of the upper canine and functional difficulties related to 
Elyes Hassouna et al., Sch J Dent Sci, Jan, 2021; 8(1): 63-70

transversal maxillar problem and to resolve the crowding that prevents him from properly having a good hygiene habits. His medical history revealed no known major systemic disease or drug allergy.
On extra-oral examination, The patient presented no obvious asymmetries in the front view. When he smiled, he showed wide buccal corridors and a small exposure of teeth. In profile view, the patient presents a concave profile and an open nasolabial angle (Figure-1).

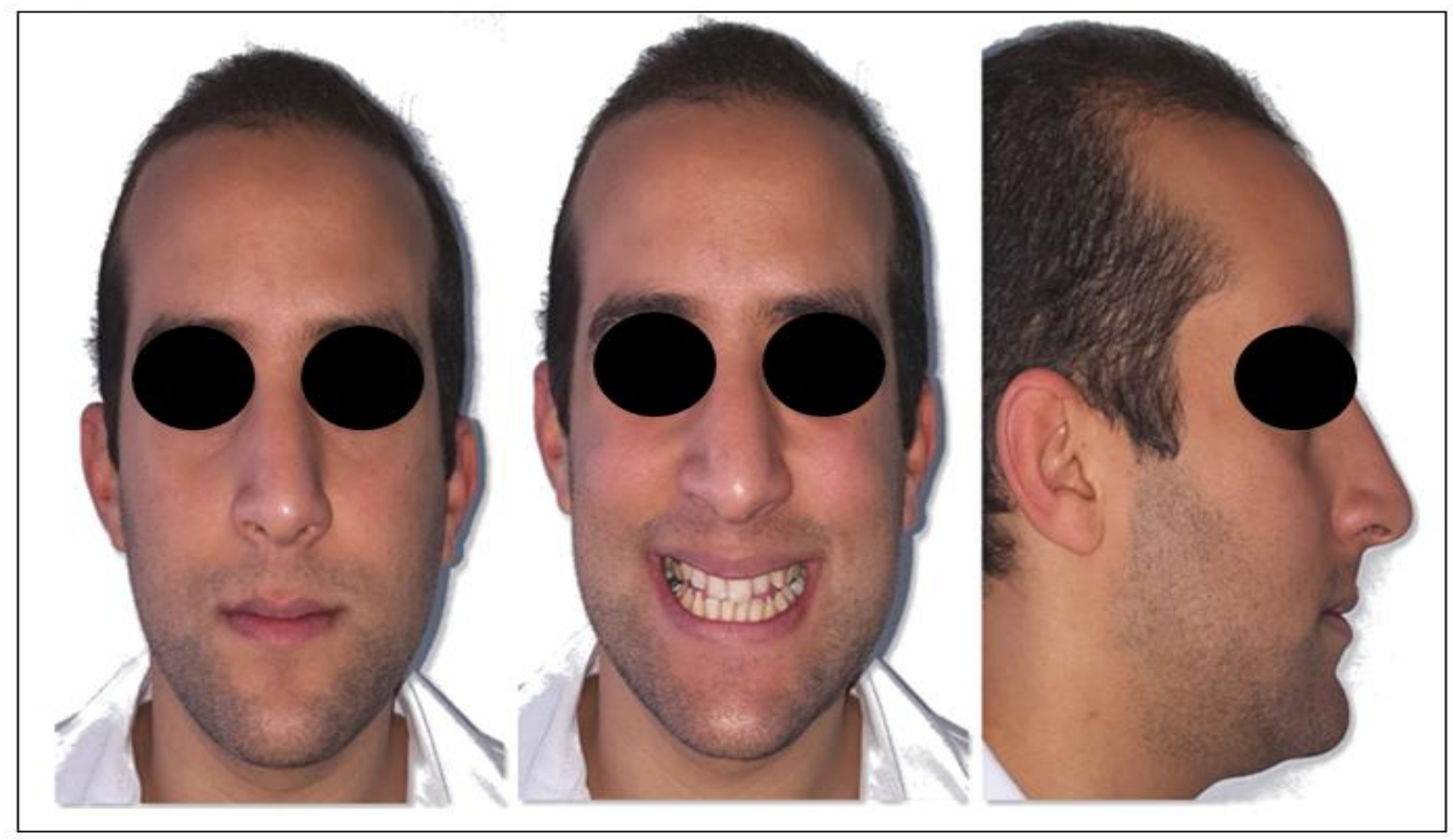

Fig-1: Extra-oral photographs taken before treatment

The intra-oral examination reveals maxillary right canine absence, no sufficient space was detected for proper alignment of upper canine in the arch an anterior crowding in the mandible and an anterior open bite. The maxilla is narrow with an ogival palate, an end-to-end anterior occlusion with a 0 to $-1 \mathrm{~mm}$ overjet and a $3 \mathrm{~mm}$ deviation of the upper midline to the right.
Examination of the functions reveals buccal respiration, the main cause of the narrow maxilla. Atypical swallowing and a history of pen interposition at the origin of the open bite (Figure-2).

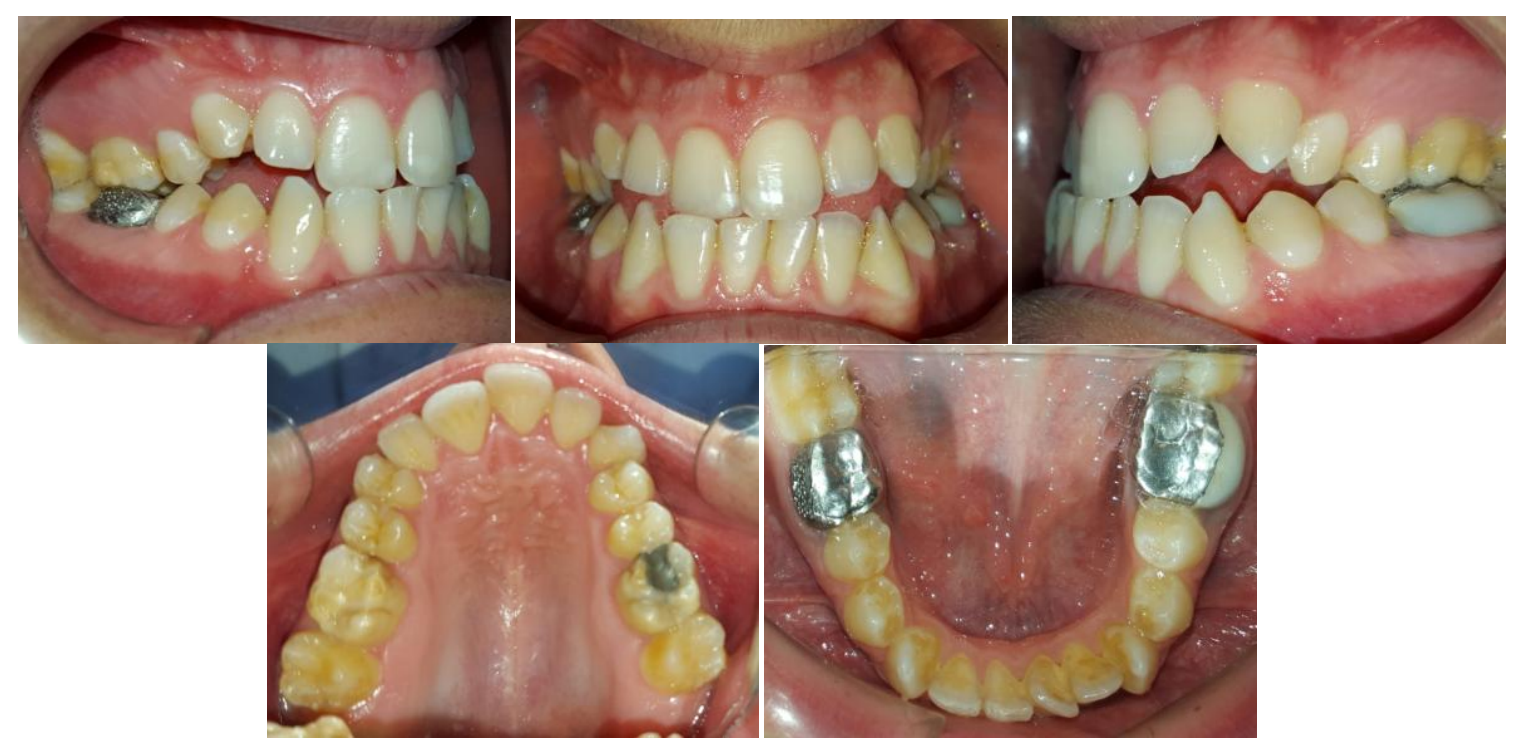

Fig-2: Intraoral photographs taken before treatment 
Orthodontic records were taken, which included maxillary and mandibular impressions, extraoral and intraoral photographs, lateral cephalogram, panoramic radiograph and cone beam computed tomography. Initial panoramic (Figure-3) revealed the presence of all permanent teeth, with the exception of the impacted upper right canine. The CBCT (Figure-4) confirmed the radiographic findings, where the right upper canine was mesially angulated, buccally displaced and in close contact with the neighboring teeth. The cephalometric evaluation (Figure-5) and the measured values revealed a Class I with a tendency to Class III skeletal pattern (ANB $=0^{\circ}$, AoBo $\left.=-2 \mathrm{~mm}, \mathrm{ANB}=80^{\circ}, \mathrm{SNB}=80^{\circ}\right)$. The mandibular plane angle and gonial angle were normal $\left(\mathrm{FMA}=26^{\circ}, \mathrm{GoGn} / \mathrm{SN}=34^{\circ}\right)$. The upper incisors were palatally tipped $\left(\mathrm{I} / \mathrm{F}=104^{\circ}\right)$, however the lower incisors were normally placed $\left(\mathrm{IMPA}=88^{\circ}\right)$.

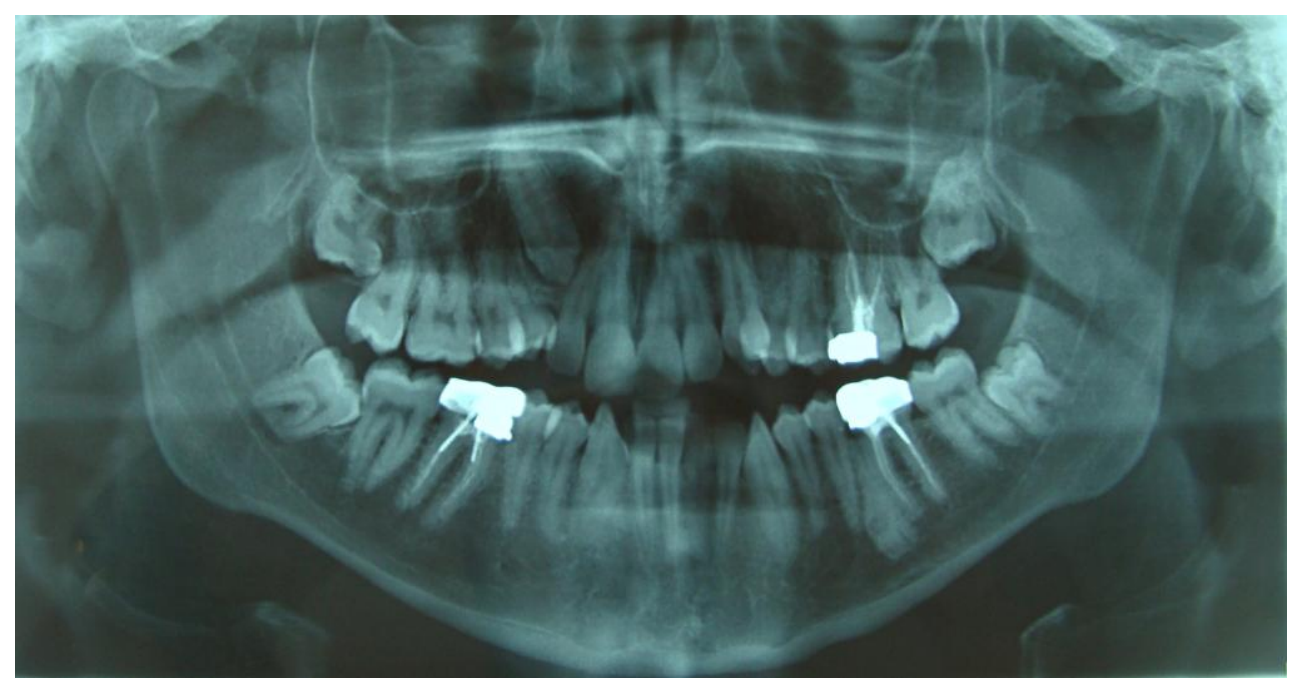

Fig-3: Panoramic radiograph before treatment

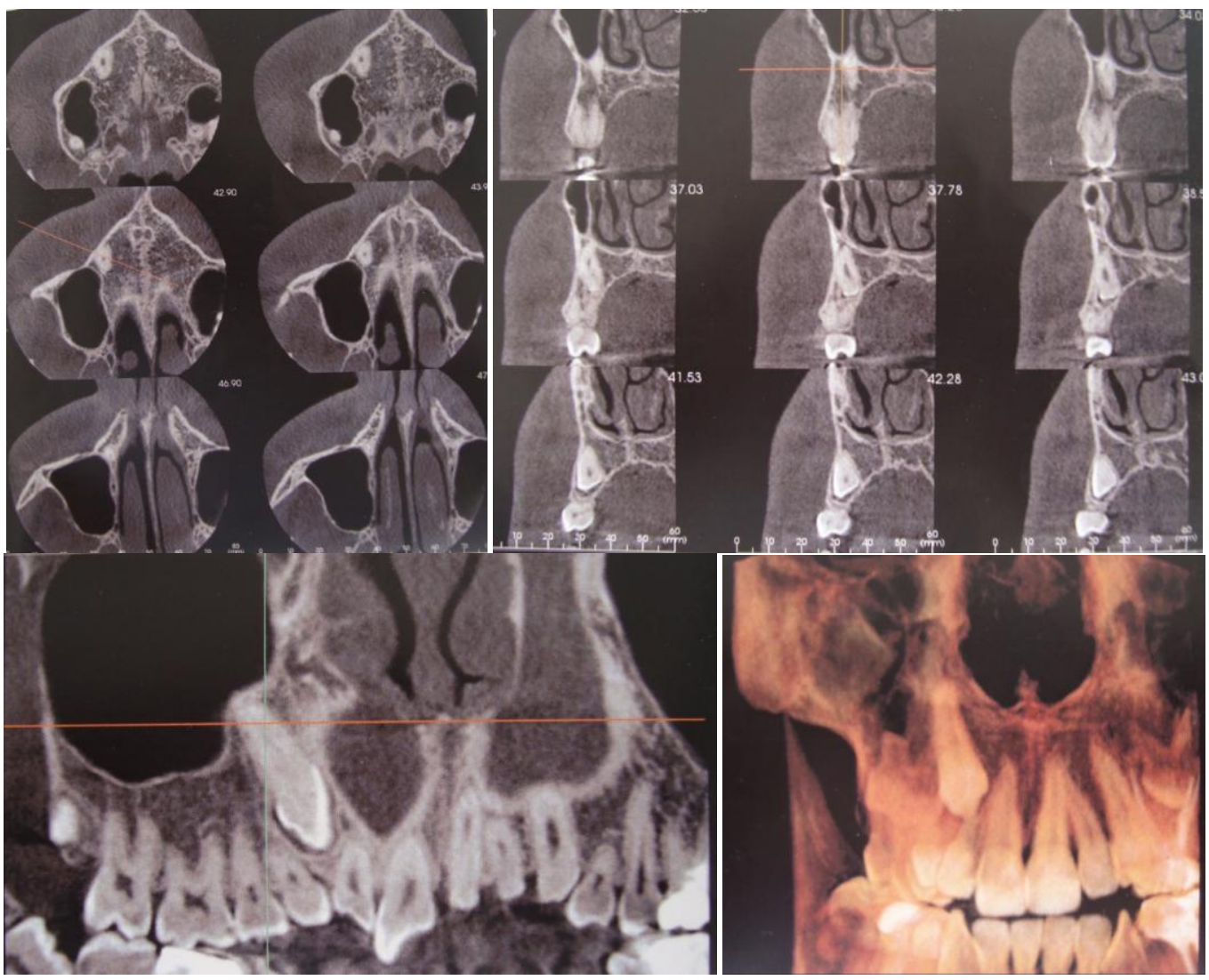

Fig-4: CBCT scan: horizontal cross-sectional slices, oblique cross-sectional slices and 3D reconstructions 


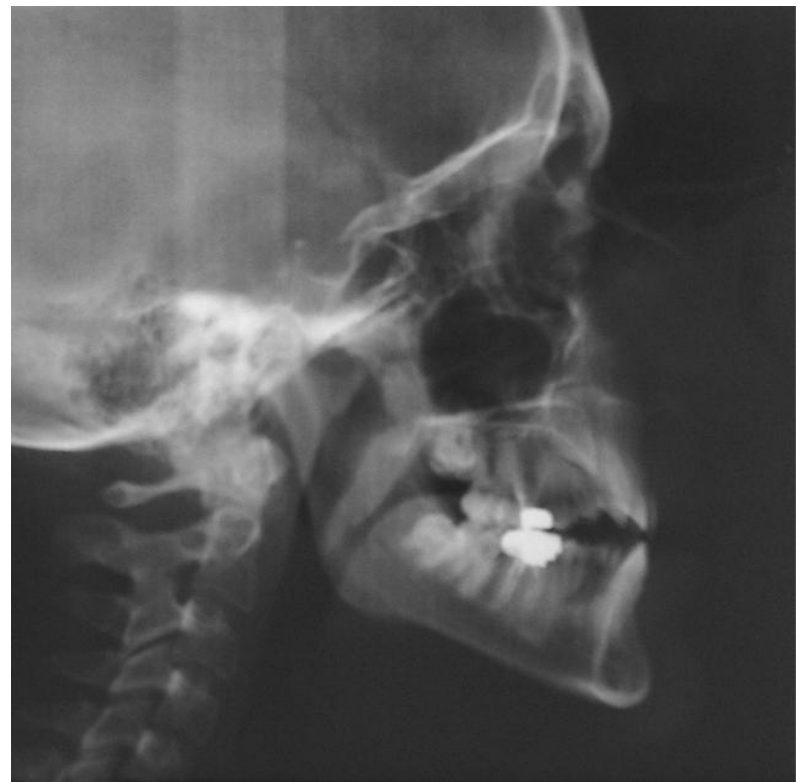

Fig-5: Initial profile cephalometric radiograph

\section{Treatment Plan}

The planning of the case was carried out taking into account all facial, skeletal and dental aspects involved. For the upper arch, it was planned to start with the quadhelix appliance and perform activations once a month for 6 months to make room for the canine. After the obtained expansion, the palatal wires were removed and the quadhelix was held in place for stabilization purpose (Figure-6). Full upper and lower fixed appliances $(0.022 * 0.028$-in slot $)$ were installed. Alignment and leveling was planned with the following sequence of archwires: .012 NiTi, .014 NiTi, .018 stainless steel, .017*.025 $\mathrm{NiTi}, .017 * .025$ stainless steel, .018*.025 stainless steel and $.019 * .025$ stainless steel. In order to do the space opening for the canine, nickel-titanium springs were planned between right lateral incisor and the first premolar, in association with the quadhelix appliance and the stripping realized on the left premolars, canine and incisors to also correct the shifting of the midline (Figure-6). As soon as adequate space was obtained for the right upper canine, the patient was referred to do the surgical exposure, corticotomy and bonding of the orthodontic attachment (Figure-7). For the traction, a rectangular stainless steel $.019 \times .025$ archwire was planned, with a zing string connected to the metal chain. Once pulled, 0.14 and $.016 \mathrm{NiTi}$, overlapped with rectangular stainless steel archwires were used to correct its position (Figure-8). Intermaxillary elastics were used to improve interdigitation (Figure-9). Fixed bar, bonded to canine to canine was used as retainers in the upper and lower arch.

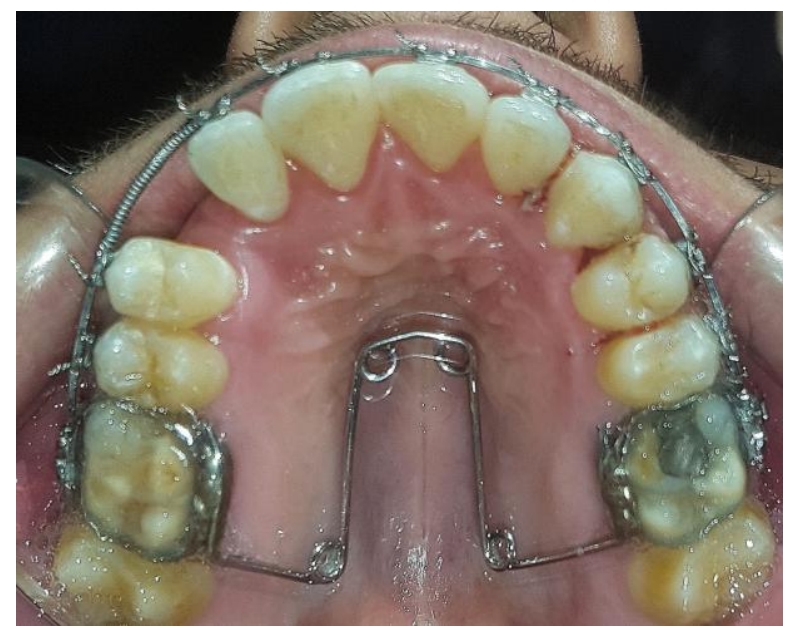

Fig-6: 6 months after the beginning of the treatment: nickel-titanium springs between right lateral incisor and the first premolar, in association with the quadhelix appliance and the stripping realized on the left premolars, canine and incisors
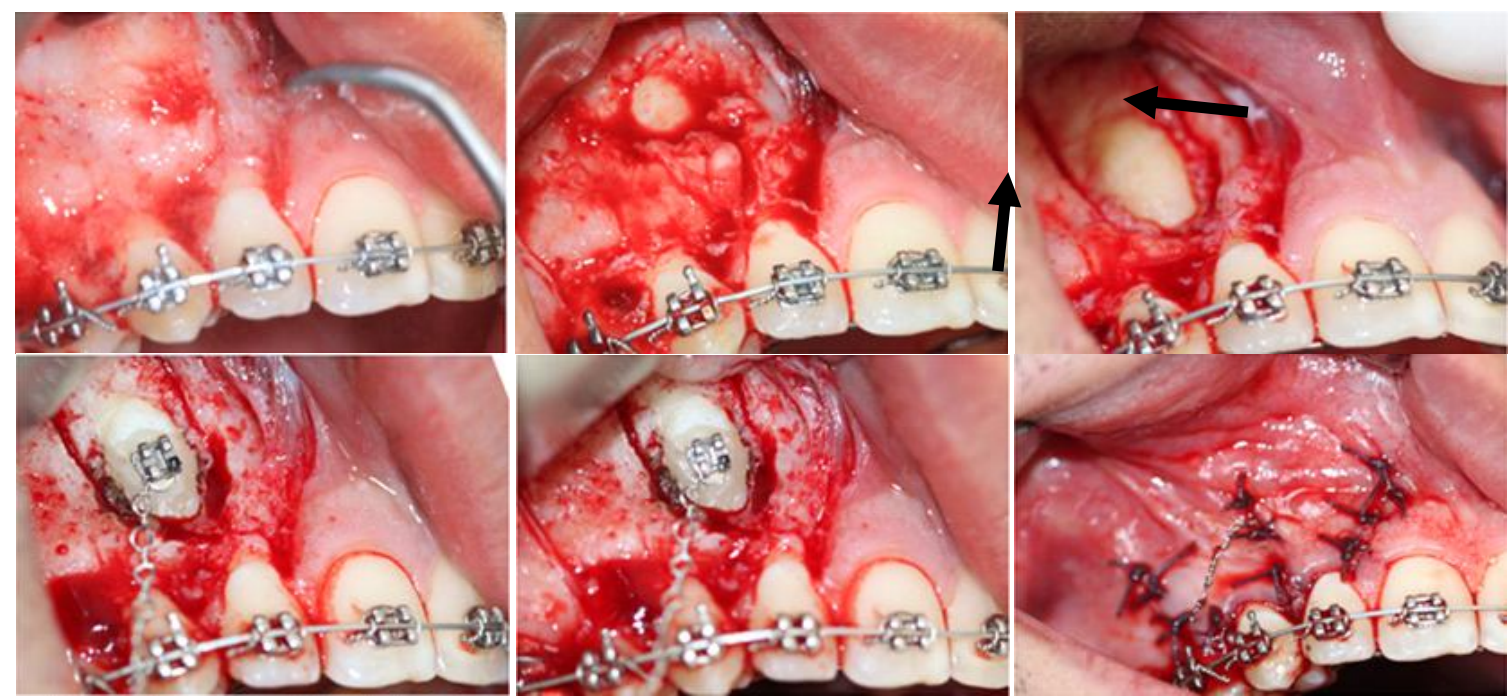

Fig-7: Surgical exposure, corticotomy and bonding of the orthodontic attachment 


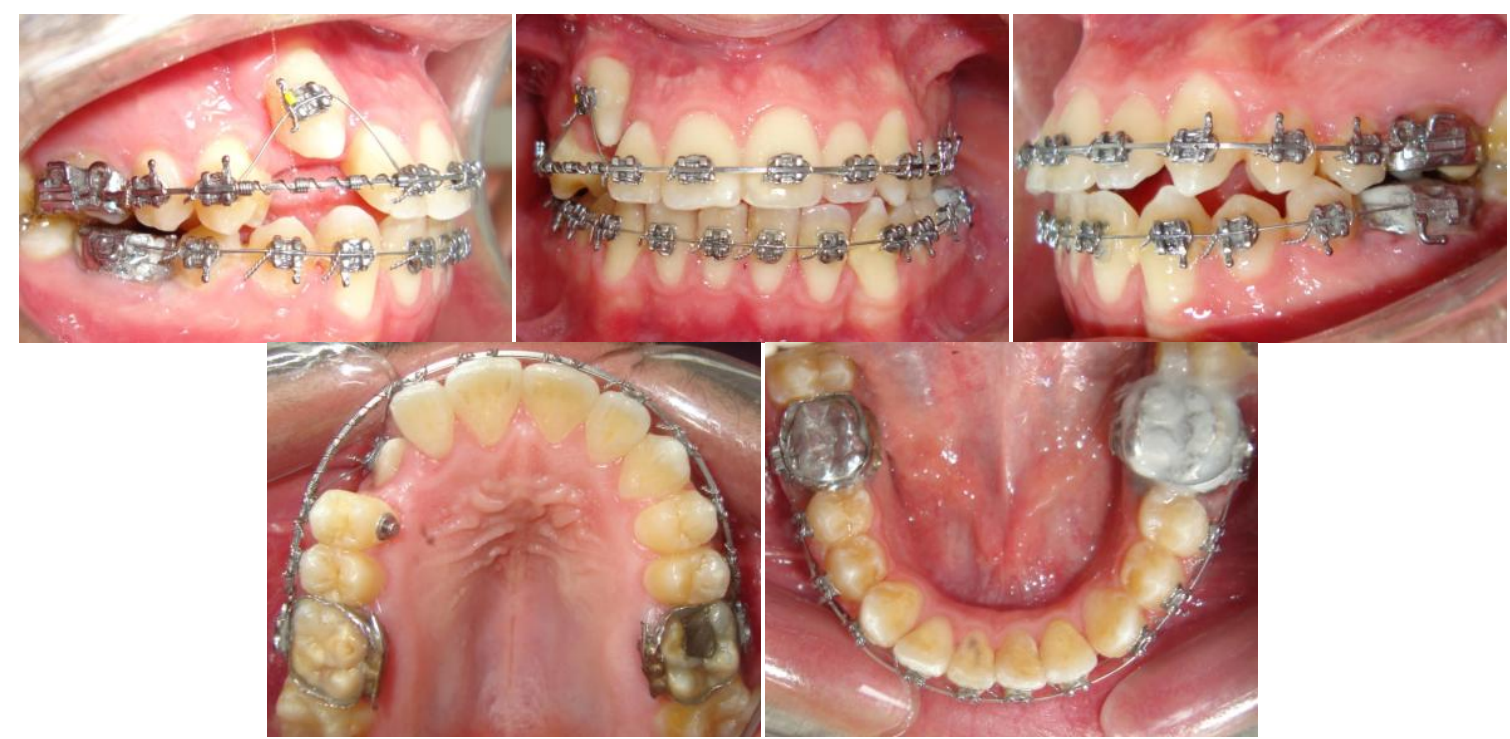

Fig-8: Traction of the canine with 0.014 NiTi overlapped with rectangular stainless steel $.019 \times \mathbf{~ . 0 2 5}$ archwire

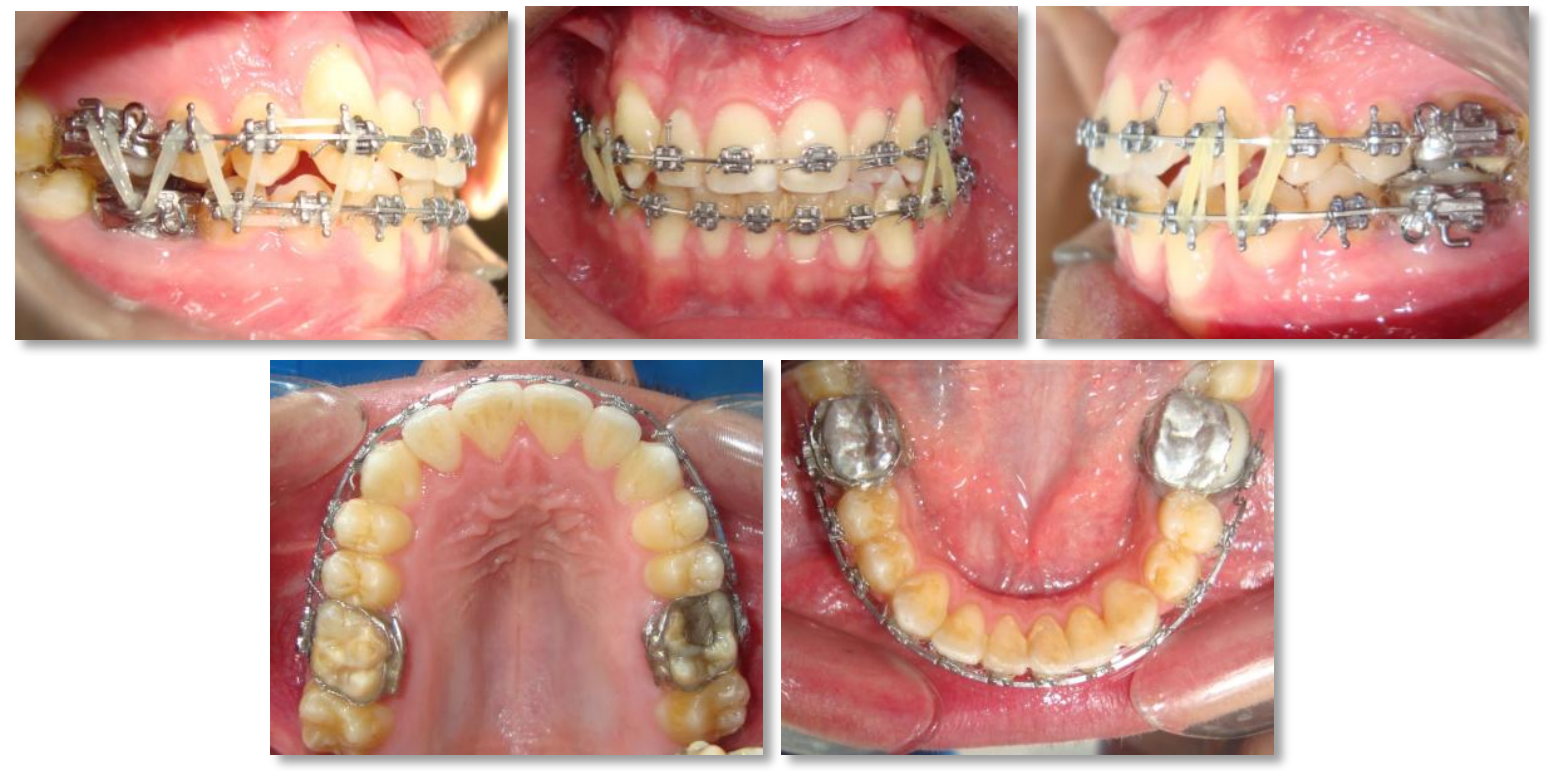

Fig-9: Intermaxillary elastics to improve interdigitation

\section{DISCUSSION}

There are several treatment options to pull the impacted maxillary canine ranging from early interceptive treatment, such as removal of the deciduous canine or rapid maxillary expansion, to surgical exposure with or without orthodontic traction to align the malpositioned tooth. No treatment and preservation of the deciduous canine is also in option in the absence of aesthetic and functional complaints or complications. Evaluation of the burden of care and treatment outcomes is paramount to the process of case selection for certain interventions, with the ultimate goal of improving the overall predictability and quality of treatment of impacted maxillary canines. The inclination of the impacted canine is reported to be one of the indicators for assessing difficulty and prognosis of the treatment. It is believed that once the tilting angle between the impacted canine and the midline exceed 25 degrees on the panoramic film, there is higher chance to witness root resorption of neighboring teeth [6] if over 45 degrees, the treatment would be extremely difficult [7]. Sarah Pitt et al., [8] suggested a treatment difficulty index (TDI) for unerupted maxillary canines based on horizontal position, age of patient, vertical height and bucco-palatal position, in descending order of importance, which determine the difficulty of canine alignment and have assigned a score ranged from 1 to 5 . The CBCT provided more detail and 3D orientation of impacted tooth for design of force delivery system and to inspect the spatial relations between the impacted canine and surrounding environment. In our case, the canine had a favorable angulation for traction but the major problem was the lack of space, in association with the open bite, shifting of the midlines and especially the high risk profile which eliminated any treatment with extraction. The space gain was obtained 
Elyes Hassouna et al., Sch J Dent Sci, Jan, 2021; 8(1): 63-70

by the quadhelix appliance in addition to stripping and transversal expansion with the archwires, which was a real challenge to achieve. Other possibility was the extraction of the premolars in the upper and lower arches to align the teeth, pull the canine and correct the crowding, but this alternative does not improve the patient profile and will even worsen it. Regarding the choice for the surgical exposure method, the correct diagnosis led to the conclusion that the closed approach was the most appropriate one. Many authors suggested this approach because it may spare patients from a new periodontal surgical procedure and promote an important structure for eruption process. It also allows traction forces to be applied on the long axis of the tooth. The duration of active orthodontic traction of maxillary impacted canine reported by most publications is an average of 8 months [9, 10]. Similarly, Luis Ernesto et al., [11] found a similar traction time of $8.40 \pm 3.26$ months. To accelerate the duration of traction, a corticotomy has been associated with the conventional surgery. A systematic review [12] carried on the effectiveness of corticotomy and piezocision on canine retraction showed that the more aggressive the surgical technique, the greater the acceleration of tooth movement was, and reported that corticotomy could accelerate tooth movement up to 4 times during the first 2 weeks. In general, corticotomy produced a rate of tooth movement 1.5 to 2 times greater than that produced by the conventional techniques. At the end of the treatment (Figure 10, 11, 14) the improvement of the face is obvious. The smile is wider and aesthetic and the profile is harmonious, balanced, with improved labial relations. The occlusion at the end of treatment is very satisfactory with a functional overjet and overbite. The smile line follows the esthetic line of the lower lip in accordance with the Zachrisson principles and the overall result is considered particularly favorable. The post treatment radiograph evaluation (Figure $12 \& 13$ ) did not show signs of external root resorption of neither the tractioned tooth nor adjacent teeth, despite some studies showing this to be the main side effect related to orthodontic traction of impacted canine.

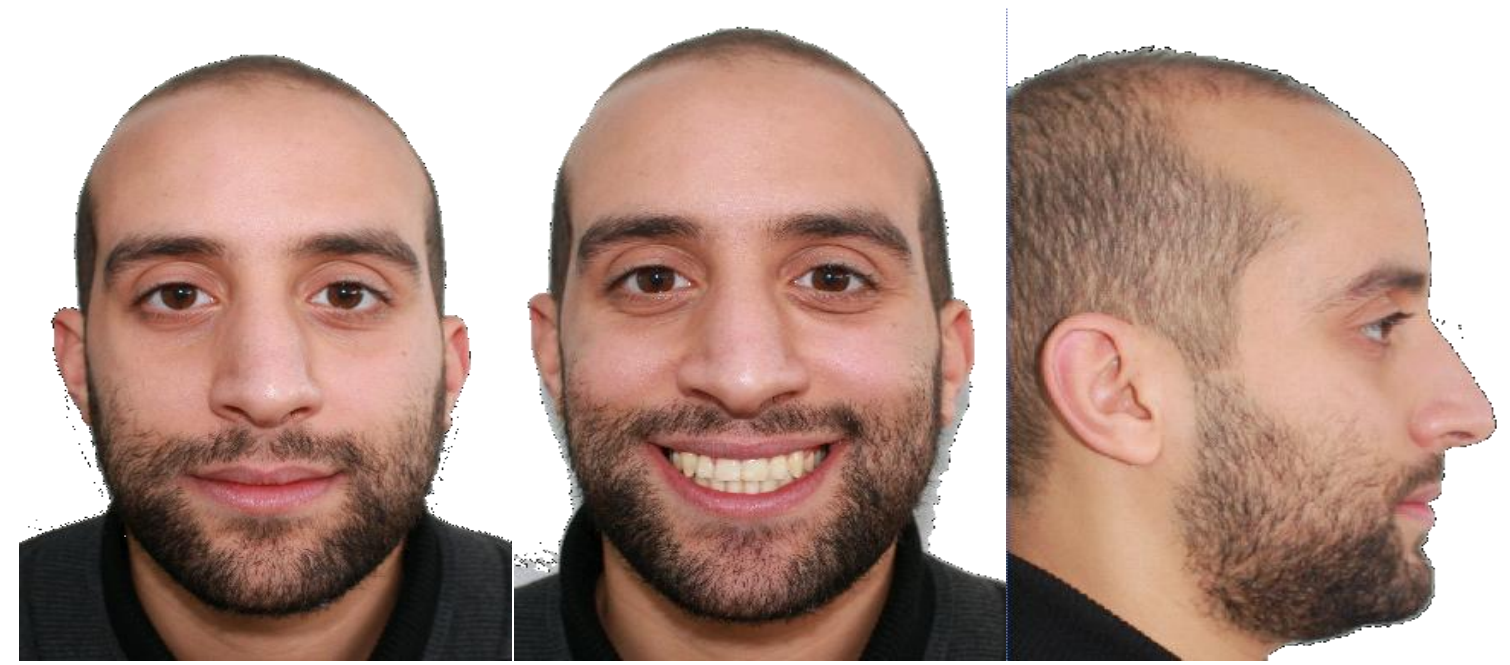

Fig-10: Extraoral photographs taken after treatment

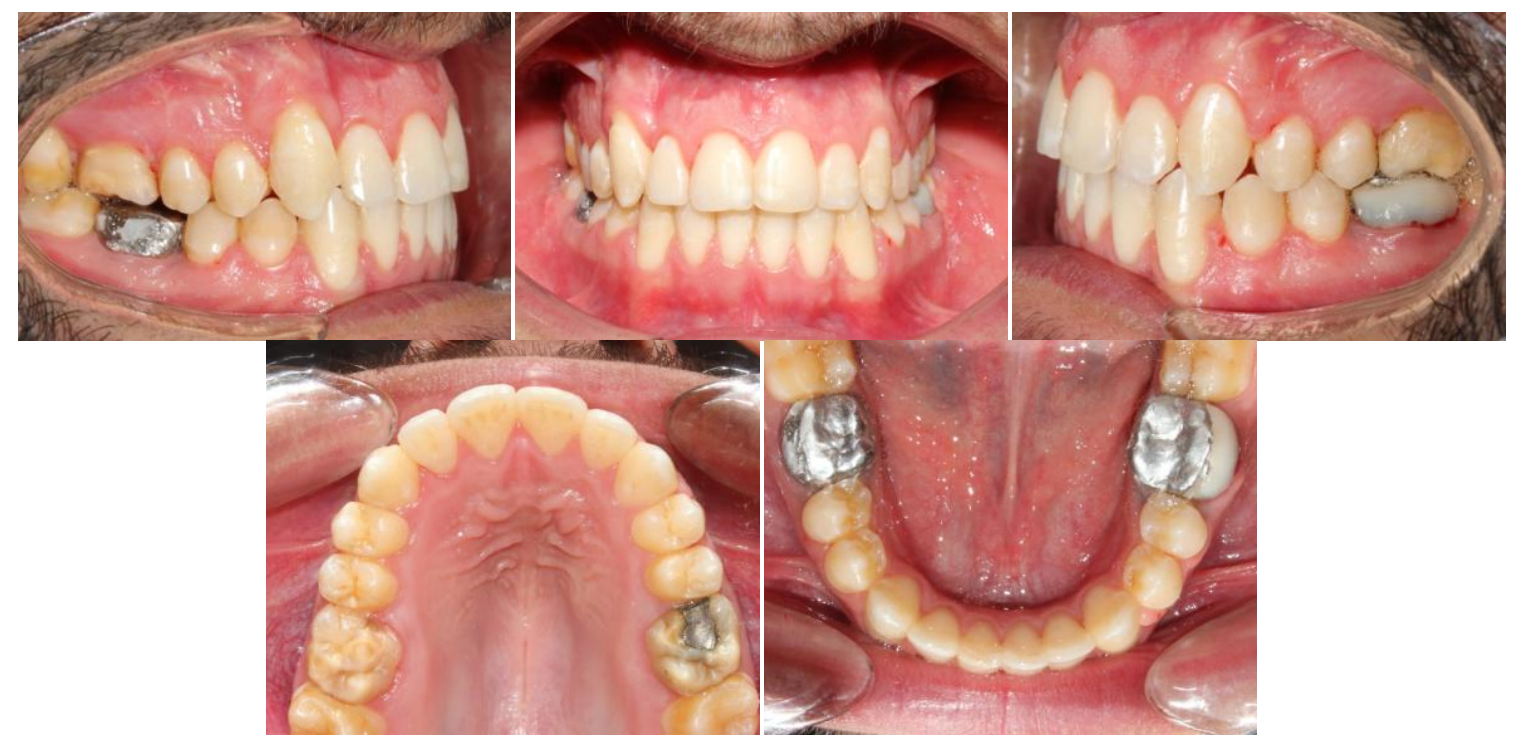

Fig-11: Intraoral photographs taken after treatment 


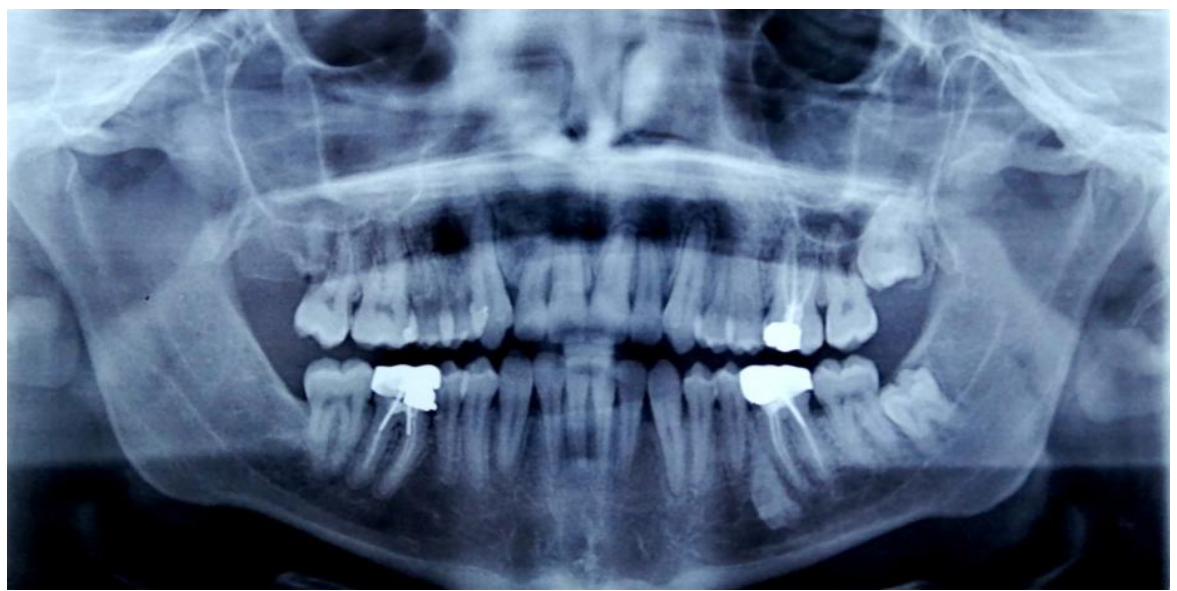

Fig-12: Panoramic radiograph after treatment

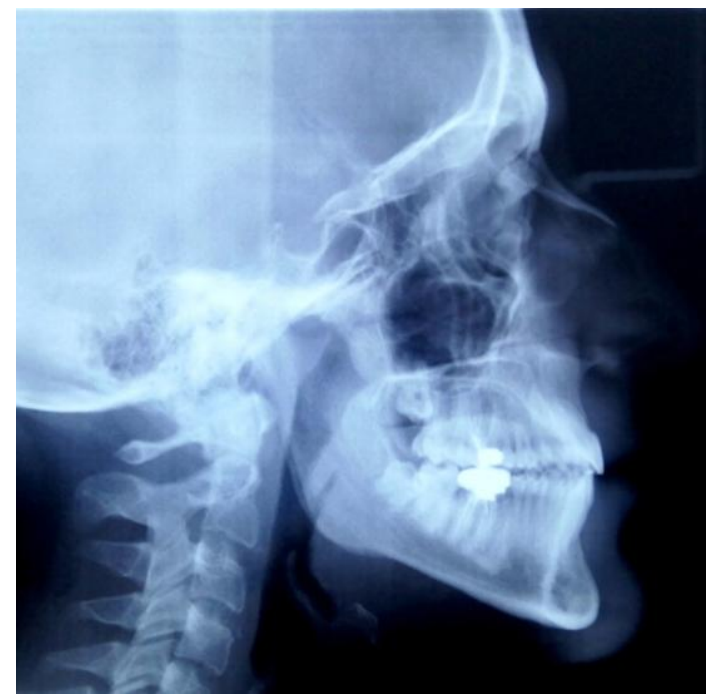

Fig-13: Profile cephalometric radiograph after treatment

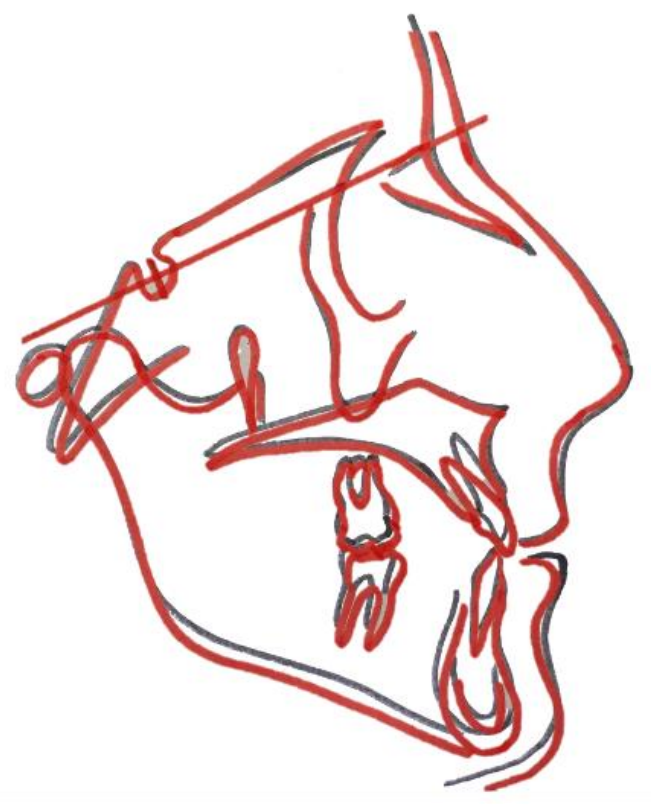

Fig-14: Superposition before and after treatment

\section{CONCLUSION}

The management of impacted canines is important in terms of esthetics and function. Clinicians should develop treatment strategies that are most beneficial to the patient and should be knowledgeable about a variety of treatments. With early detection, timely interception and well-managed surgical and orthodontic treatment, impacted maxillary canines can be allowed to erupt and be directed to the appropriate position on the arch. However, the success of the treatment is only obtained with proper multidisciplinary care of general dentists and specialists.

\section{REFERENCES}

1. Litsas G. A review of early displaced maxillary canines: Etiology, diagnosis and interceptive treatment. Open Dent J. 2011; 5:39-47.

2. Bishara SE. Impacted maxillary canines: a review. Am J Orthod Dentofacial Orthop. 1992 Feb; 101(2):159-71.

3. Cruz RM. Orthodontic traction of impacted canines: Concepts and clinical application. Dental press journal of orthodontics. 2019 Feb;24(1):7487.

4. Ericson S, Kurol J. Early treatment of palatally erupting maxillary canines by extraction of the primary canines. Eur J Orthod. 1988 Nov; 10(4):283-95

5. Abbas NH, Sabet NE, Hassan IT. Evaluation of corticotomy-facilitated orthodontics and piezocision in rapid canine retraction. American Journal of Orthodontics and Dentofacial Orthopedics. 2016 Apr 1;149(4):473-80.

6. Bedoya MM, Park JH. A review of the diagnosis and management of impacted maxillary canines. J Am Dent Assoc. 2009; 140:1485-1493. 19.

7. Alessandri Bonetti G, Zanarini M. Danesi M, Parenti SI, Gatto MR. Percentiles relative to maxillary permanent canine inclination by age: A radiographic study. Am J Orthod Dentofacial Orthop. 2009; 136:442-6. 
8. Pitt S, Hamdan A, Rock P. A treatment difficulty index for unerupted maxillary canines. The European Journal of Orthodontics. 2006 Apr $1 ; 28(2): 141-4$.

9. Nieri M, Crescini A, Rotundo R, Baccetti T, Cortellini P, Pini Prato GP. Factors affecting the clinical approach to impacted maxillary canines: a bayesian network analysis. Am J Orthod Dentofacial Orthop. 2010; 137:755-62.

10. Crescini A, Nieri M, Buti J, Baccetti T, Pini Prato GP. Orthodontic and periodontal outcomes of treated impacted maxillary canines. Angle Orthod. 2007; 77:571-7.
11. Arriola-Guillén LE, Aliaga-Del Castillo A, RuízMora GA, Rodríguez-Cárdenas YA, Dias-Da Silveira HL. Influence of maxillary canine impaction characteristics and factors associated with orthodontic treatment on the duration of active orthodontic traction. American Journal of Orthodontics and Dentofacial Orthopedics. 2019 Sep 1;156(3):391-400.

12. Viwattanatipa N, Charnchairerk S. The effectiveness of corticotomy and piezocision on canine retraction: A systematic review. Korean journal of orthodontics. 2018 May;48(3):200-211. 